\title{
A CASE OF PROBABLE ANTENATAL TUBERCULOUS INFECTION.
}

BY

\author{
R. H. MORLEY, M.B., B.S.
}

(From the Department of Pathology and Bacteriology, The University of Leeds.)

The following case of miliary tuberculosis in an infant of six weeks old presents several unusual features of interest. The possibility of antenatal infection from the placenta is now regarded as established, though of rare occurrence, and in the case here reported seems the most reasonable explanation of very advanced lesions in so young a subject.

Clinical history.-The child, a male, was born at home on Decomber 20th, 1928, at full term and weighed $7 \mathrm{lb}$. Delivery was normal and the doctor in attendance noticed nothing unusual about the child or the placenta. The child was wholly breist fed and developed satisfactorily until 4 weeks old, when he began to fall off, with diarrhœa, loss of weight and inability to take his food, and at this time a patent food was substituted for the breast milk. One week later, on January 26th, 1929, he was admitted to hospital where he went steadily from bad to worse, being unable to take nourishment and running a temperature up to $102^{\circ} \mathrm{F}$. He died on January 31st and an autopsy was performed on the following day.

Summary of post-mortem examination.-The peritoneal cavity contained a few ounces of clear straw-coloured fluid. The liver showed a generalized tuberculous lesion in the form of rather irregular crude and miliary tubercles, 1 to $4 \mathrm{~mm}$. in diameter, scattered throughout its substance. The cœliac glands lying between the head of the pancreas and the portal fissure showed an advanced caseating tuberculous lesion with central cavitation. The spleen contained innumerable crude and miliary tubercles up to $4 \mathrm{~mm}$. in diameter. The kidneys contained a few small scattered tubercles definitely of crude caseous type, the largest being 2-3 mm. in diameter. The mesenteric glands showed a few small caseous tuberculous foci, much smaller and more recent than those in the cœliac group. The lungs contained numerous crude yellow tubercles up to $7 \mathrm{~mm}$. in diameter, together with many fine miliary tubercles. The bronchial glands were the seat of early caseating tuberculosis. In addition there were scattered miliary tubercles in the adrenals, the gastric and intestinal mucosæ, the pleuræ and the myocardium. The most advanced lesion was certainly that of the cœliac group of glands.

Histological examination. - The liver is uniformly studded with tubercles in which may be distinguished two types of response, occasionally associated in the same tubercle but most frequently occurring separately. (1) There is a definite and typical follicle with epithelioid cells, slight necrosis, formation of giant cells of small size and a little peripheral lymphocytic infiltration. These tubercles stain pink with hæmalum and eosin, and contain only an occasional tubercle bacillus. (2) Secondly, there is a lesion which is essentially necrotic with very notable basic staining on account of the abundant pyknotic nuclear material present. In this form tubercle bacilli are present in myriads but there is little cellular reaction and no giant cells are seen. There is considerable lymphocytic infiltration of the portal tracts. The lobular arrangement of the hepatic cells is disturbed and they show fatty degeneration.

The mass of coliac glands is largely caseous and contains many tubercle bacilli. The adrenals are sparsely studded with miliary tubercles in which necrosis is the outstanding feature with notable absence of lymphocytic, endothelial cell, and giant cell reaction. Tubercle bacilli are present in large numbers. The spleen contains numerous large necrotic tubercles. They present the same general characteristics as those in the adrenals. Tubercle bacilli are present in large numbers. The lungs show aggregated tubercles, of varying size, having the same characteristics as those in adrenals and spleen. Many of the alveoli are filled with caseous plugs. Tubercle bacilli are more numerous in this than in any other organ. 
It is fairly certain that the two types of lesion in the liver are of different ages (1) being of some weeks standing, and (2) probably only a few days to a week or so. The lesions observed in the other organs correspond in general to those of the second type in the predominance of necrosis with little reaction and in the presence of enormous numbers of bacilli.

Family history.-All four grandparents are healthy and living. The mother, aged 25, has been married for two years and this was the first child. She is of healthy appearance and gives no medical history of note. Of her own family, father, mother, two brothers and a sister are all healthy and there have been no deaths. The physical examination, including X-ray examination of the chest and sputum tests, is entirely negative..

The father, aged 28, a tram driver, is of healthy appearance and has also no medical history of note. His father, mother, four brothers and sisters are all healthy. Three died in infancy of unknown causes. On examination, he is fairly well developed. There is some flattening of the left chest and slight impairment of resonance at the apex, without adventitious signs. The sputum contains no tubercle bacilli. An X-ray of the chest shows increased root shadows on the left side but no sign of active phthisis.

\section{Discussion.}

The argument for an antenatal infection is based on the early age at death and the anatomical characters and distribution of the lesions.

Age. It seems very unlikely that lesions so advanced as those in the liver and cœliac glands could have originated within six weeks of death.

Anatomical distribution. The most striking feature of the morbid anatomy is the extent to which the cœliac group of glands was affected, whereas in the mediastinal and mesenteric groups the process was both slighter and more recent. This suggests a direct infection from the placenta and as, in the absence of lymphatics in the umbilical cord, the infection must have been blood-borne, evidence of antecedent infection of the liverwould beexpected. Here it is to be found in the first of the two types of lesion above described, well formed tubercles with giant cells and abundant epitheliod cells. It is assumed that these lesions were produced by lodgement in the liver of tubercle bacilli passing in the umbilical veins from the placenta, that the portal and cceliac glands were infected by drainage from the liver and that miliary dissemination took place therefrom, probably via the thoracic duct, with production of the second type of lesion. In this connection the numbers of bacilli in the two types is worthy of comment, only one or two being seen in the older original tubercles and enormous numbers in the recent lesions. The fact that the placenta was not obviously diseased is not surprising, as reference to Warthin's ${ }^{2}$ account of placental tuberculosis shows that frequently there is no naked-eye evidence and that histologically tubercles are sometimes found in the walls of chorionic vessels thus providing ready access to the umbilical blood-stream.

To explain antenatal infection it seems necessary to assume either $(a)$ a general blood infection of the mother, $(b)$ genital tract infection of the mother, or $(c)$ genital tract infection of the father, though this must be a rare cause.

Actually, physical examination of the parents was strikingly negative, they both feel perfectly well and the whole affair is an inexplicable mystery to them. Certainly a general tuberculous infection of either, and genital tract infection of the father can be excluded, and the only possibility that remains 
is that the mother suffers from some latent tuberculosis of the genital tract. And if evidence of antenatal infection is lacking, so is that of post-natal, for the home surroundings were reasonably healthy, the child never came in contact with a recognized tuberculous subject, and moreover, was entirely breast-fed until the onset of symptoms.

In connection with this case it is interesting to refer to reviews of supposed cases of congenital tuberculosis. In 1904 Warthin and Cowie $^{3}$ reviewed the cases reported up till then, the list including five undoubted cases and thirtyone probable or doubtful cases. In none of these was the mother specifically stated to be healthy.

Since then a very large number of cases has been reported and Calmette and others ${ }^{1}$ in 1926 , following up the histories of 100 pregnant tuberculous women, found abortion, still-birth or death in infancy in twenty-one : autopsy was performed on nine of these infants and in only three were tubercle bacilli demonstrated. In this and similar investigations only the children of frankly tuberculous mothers have been examined, and the present case is especially interesting in that it was accidentally brought to light.

SUMMARY.

The chief points of interest in the case are as follows :-

1. The likelihood, from the foregoing considerations, of its being one of antenatal infection.

2. The complete absence of signs or symptoms of tuberculosis in the mother.

3. The apparent healthiness of the child at birth.

4. The evidence of two stages in the infection of the infant, a definitely older lesion in the liver with well-marked cellular reaction, presumably antenatal and of placental origin, and a very recent general miliary tuberculosis in which the lesions are necrotic in type and, in contradistinction to the others, contain tubercle bacilli in enormous numbers.

I am much indebted to Dr. Vining, under whose care the child was admitted to the Leeds General Infirmary, for permission to publish the case.

\section{REFERENCES.}

1. Calmette, A., Valtis, J. and Lacomme, M., Presse Medicale, Paris, 1926, XXXIV, 1409.

2. Warthin, A. S., J. Infect. Dis., ('hicago, 1907, IV, 347.

3. Warthin, A. S., and ('owie, D. M., Ibid, 1904, I, 140. 